Research Article

\title{
Exploiting the Chain Convenience Store Supplier Selection Based on ANP-MOP Model
}

\author{
Yaqin Ou $\mathbb{D I}^{1}$ and Bo Liu $\mathbb{D D}^{2}$ \\ ${ }^{1}$ School of Business Administration, Chaohu College, Chaohu 238000, China \\ ${ }^{2}$ School of Information Engineering, Chaohu College, Chaohu 238000, China \\ Correspondence should be addressed to Bo Liu; 623321161@qq.com
}

Received 29 January 2021; Revised 26 February 2021; Accepted 6 May 2021; Published 19 May 2021

Academic Editor: Zong-Yao Sun

Copyright (C) 2021 Yaqin Ou and Bo Liu. This is an open access article distributed under the Creative Commons Attribution License, which permits unrestricted use, distribution, and reproduction in any medium, provided the original work is properly cited.

\begin{abstract}
The purchase cost of chain convenience stores accounts for a large proportion of the total cost. Enterprises are facing the problem of how to reasonably reduce the purchase cost while ensuring the quality of service. This paper first considers the uniqueness of chain convenience stores, draws on existing research results, and establishes an evaluation index system for chain convenience store suppliers through field research. Then, we use the principal component analysis method of selection to determine the weight of each index and make a preliminary ranking of the importance of chain convenience store suppliers. Secondly, according to the relevant weights determined by the network hierarchy method, the collected data are substituted into the multiobjective mathematical programming model to analyze the distribution of supplier procurement and calculate the procurement cost. The level of procurement expenditures accounted for by suppliers confirms the importance of suppliers. The results show that through the evaluation and ranking of suppliers and the effective management of suppliers according to the ranking results, not only the goal of cost minimization is achieved but also the reasonable service level is guaranteed, which is scientific.
\end{abstract}

\section{Introduction}

The beginning of the entire supply chain management is the selection of suppliers. Among all types of enterprises, the purchase cost of chain retail accounts for the largest total cost. The current research on supplier evaluation and selection in chain retail is not thorough enough. Especially in chain retail, the research on supplier selection based on the two major factors of procurement cost and service level, procurement allocation, and follow-up management is very much lacking [1-3].

Guo used AHP to conduct preliminary supplier selection and comprehensive supplier selection and determined its primary and alternative suppliers [4]. Liao and Zhang adopted the AHP-TOPSIS composite method to determine the weight of each index, thus constructing a standardized model for evaluating and selecting green suppliers for papermaking enterprises. And through the application of empirical examples, the feasibility of the way is verified, and an effective method is provided for papermaking enterprises to choose green suppliers [5]. Zhou and Liao used the analytic hierarchy process (AHP) to calculate the weight of a total of 14 indicators in 5 categories, including green environmental indicators, and built an objective and operable supplier evaluation process [6]. Song used the AHP and took candy products as an example to conduct an empirical analysis of the supplier evaluation index system [7]. From the current research on the evaluation of supplier selection by scholars, most scholars still use AHP to construct the supplier index system; still, AHP cannot fully consider the interrelationship between the various index systems. More importantly, most of the scholars' evaluation and selection of suppliers is aimed at manufacturing companies, ignoring the high proportion of chain retail purchase costs in total costs [8-12].

From the existing supply chain management research, according to the current supply chain management research, there is not much research on the selection management of chain retail suppliers whose procurement costs account for the 
total costs. Therefore, it is necessary to further explore the evaluation and selection of chain retail suppliers. This paper takes chain convenience stores in chain retail as an example to examine the evaluation choices of chain convenience store suppliers. The content of this paper is arranged as follows. In Section 2, ANP is described in detail and is used to construct, select, and determine the weight of the supplier's index system. In Section 3, firstly, MOP model is constructed based on ANP model; secondly, taking Rosen, the leader in chain convenience stores, as an example, the collected relevant data which are substituted into the MOP to determine the weight of its supplier evaluation index system and the allocation of procurement volume. The empirical results analysis is presented in Section 4, and a summary of this paper is given in Section 5.

\section{ANP Model Construction}

2.1. ANP Model Construction and Index Optimization. The elements $p_{1}, p_{2}, \ldots, p_{n}$ are in the ANP control layer, and the elements $c_{1}, c_{2}, \ldots, c_{n}$ are in network layer, where $c_{1}$ has elements $e_{i 1}, e_{i 2}, \ldots, e_{i n}$, where $i=1,2, \ldots, N$. The criterion is the control layer $p_{s}(s=1,2, \ldots, m)$, and the secondary criterion is the element $e_{j l}\left(l=1,2, \ldots, n_{j}\right)$. The elements in the element group $c_{i}$ are compared according to their influence on $e_{j l}$, and the judgment matrix $[13,14]$ is constructed under the criterion ps, as shown in Table 1.

$$
\begin{aligned}
& W_{i j}=\left[\begin{array}{cccc}
w_{i 1}^{(j 1)} & w_{i 1}^{(j 2)} & \ldots & w_{i 1}^{(j n i)} \\
w_{i 2}^{(j 1)} & w_{i 2}^{(j 2)} & \ldots & w_{i 2}^{(j n i)} \\
& & \vdots & \\
w_{i n_{j}}^{(j 1)} & w_{i n_{j}}^{(j 2)} & \ldots & w_{i n_{j}}^{(j n i)}
\end{array}\right], \\
& \begin{array}{lll}
C_{1} & C_{2} & C_{N}
\end{array} \\
& \begin{array}{lllllllll}
e_{11} & \ldots & e_{1 n_{1}} & e_{21} & \ldots & e_{2 n_{2}} & e_{N 1} & \ldots & e_{N n_{n}}
\end{array} \\
& e_{11} \\
& C_{1} \quad \ldots \\
& W=C_{2} \begin{array}{c}
e_{1 n_{1}} \\
e_{21} \\
\ldots \\
e_{2 n_{2}} \\
e_{N 1}
\end{array}\left[\begin{array}{ccccc}
W_{11} & W_{12} & \ldots & W_{1 N} \\
W_{21} & W_{22} & \ldots & W_{2 N} \\
\vdots & \vdots & & \vdots \\
W_{N 1} & W_{N 2} & \ldots & W_{N N}
\end{array}\right] . \\
& C_{N} \quad \cdots \\
& e_{N n_{n}}
\end{aligned}
$$

The weight vector is obtained by the characteristic-root method. Repeat the above steps to obtain the matrix record as shown in formula (1):

The column vector of here is the sorting vector of the

\begin{tabular}{|c|c|c|}
\hline$e_{i j}$ & $e_{i 1}, e_{i 2}, \ldots, e_{i n_{j}}$ & Normalized feature vector \\
\hline$e_{i 1}$ & & $w_{i 1}^{(j i)}$ \\
\hline$e_{i 2}$ & & $w_{i 2}^{(j i)}$ \\
\hline$\vdots$ & & \\
\hline$e_{i n_{i}}$ & & $\dot{w}_{i n_{i}}^{(j i)}$ \\
\hline
\end{tabular}
influence degree of the element in the element. If the middle element is not affected by the middle element, then $=0$. Repeat the above steps for $i=1,2, \ldots, \mathrm{N}, j=1,2, \ldots, \mathrm{N}$. Finally, the supermatrix under the criterion can be obtained as equation (2). There are $m$ of these supermatrices, and they are all nonnegative matrices.
TABLE 1: Judgment matrix between each element.

2.2. Construction and Optimization of Evaluation Index System. On the basis of summarizing the research of scholars, a questionnaire was designed in combination with the characteristics of chain convenience stores; after distribution, recovery, and calculation, the evaluation index system of chain convenience store procurement suppliers was initially constructed [9-13] (as shown in Table 2).

In response to the initially constructed indicator system, a questionnaire on the importance of indicators was designed and distributed to multiple experts to score them. Then, the questionnaire was returned to the minimum and maximum statistics of all indicators, and mean and standard deviation were calculated. By comparing and analyzing the results, the criterion layer and the index layer are selected to obtain a new and more realistic index system [14-17], and then the data on the importance of the criterion layer and the index layer are sorted out.

Table 3 shows the mean and standard deviation of the importance scores of the five categories of indicators by respondents. It can be seen from the table that the mean (8.13) of the price factor is the largest, which is almost close to the maximum value of 9.00 , which also shows that price is the most crucial consideration. Secondly, the larger mean is cooperation ability (7.31), which shows that the cooperation ability is also vital. The mean of technical ability (7.11) and the mean of cooperation ability (7.31) are very close in size, so they are even more important. However, the internal competitiveness (3.11) and external competitiveness (4.07) have a smaller mean.

The standard deviation of price factor, cooperation ability, and internal competitiveness is relatively small. It can be seen that the respondents have basically no objection to the importance of these three indicators, while the standard deviation of external competitiveness and technical ability is relatively large, indicating that interviewers have a specific difference in their opinions on the importance of these two indicators.

In the same way, the subdivision secondary indicators of other standard levels are shown in Table 4.

\subsection{Establishment of the Index Weights for Supplier Evaluation} Index System. The following only lists the evaluation data of one group of five groups of experts on the pairwise comparison matrix of the criterion-level indicators. The evaluation data of all indicators are directly input into the software for calculation [18-21]. The calculation results are shown in Table 5 . The indicators of the standard level in the software are technical capabilities $B_{1}$, cooperation capabilities $B_{2}$, external competitiveness $B_{3}$, internal competitiveness $B_{4}$, and price factors $B_{5}$. 
TABLE 2: Evaluation index system for purchasing suppliers of chain convenience store.

\begin{tabular}{|c|c|c|c|}
\hline Target layer & Criterion layer & Index layer & Indicator type \\
\hline \multirow{24}{*}{ Supplier selection evaluation } & \multirow{5}{*}{ Technical skills B1 } & Logistics facilities and equipment $\mathrm{C} 1$ & Qualitative \\
\hline & & Information team processing ability $\mathrm{C} 2$ & Qualitative \\
\hline & & Proportion of supply chain management professionals C3 & Qualitative \\
\hline & & Scheme design ability $\mathrm{C} 4$ & Qualitative \\
\hline & & Process integration capability C5 & Qualitative \\
\hline & \multirow{5}{*}{ Teamwork ability B2 } & Supply capacity C6 & Qualitative \\
\hline & & Reliability C7 & Qualitative \\
\hline & & After-sales service C8 & Qualitative \\
\hline & & Delivery accuracy C9 & Quantitative \\
\hline & & Quick response ability $\mathrm{C} 10$ & Qualitative \\
\hline & \multirow{5}{*}{ Internal competitiveness B3 } & Operating resources $\mathrm{C} 11$ & Qualitative \\
\hline & & R \& D capabilities C12 & Qualitative \\
\hline & & Production management ability $\mathrm{C} 13$ & Qualitative \\
\hline & & Organizational effectiveness analysis $\mathrm{C} 14$ & Qualitative \\
\hline & & Operational capability $\mathrm{C} 15$ & Qualitative \\
\hline & \multirow{4}{*}{ External competitiveness B4 } & Market environment and competition $\mathrm{C} 16$ & Qualitative \\
\hline & & Customer needs and feedback C17 & Qualitative \\
\hline & & Economic environment $\mathrm{C} 18$ & Qualitative \\
\hline & & Social environment C19 & Qualitative \\
\hline & \multirow{5}{*}{ Price factor B5 } & Transportation cost $\mathrm{C} 20$ & Quantitative \\
\hline & & Product cost $\mathrm{C} 21$ & Quantitative \\
\hline & & Storage cost $\mathrm{C} 22$ & Quantitative \\
\hline & & Quality cost C23 & Quantitative \\
\hline & & Out-of-stock cost C24 & Quantitative \\
\hline
\end{tabular}

TABLe 3: Descriptive statistical analysis of criterion-level indicators.

\begin{tabular}{|c|c|c|c|c|c|}
\hline & Technical skills & Teamwork ability & Internal competitiveness & External competitiveness & Price factor \\
\hline Number & 100 & 100 & 100 & 100 & 100 \\
\hline Minimum & 4 & 5 & 2 & 3 & 7 \\
\hline Maximum & 9 & 9 & 5 & 8 & 9 \\
\hline Mean (mean) & 7.11 & 7.31 & 3.11 & 4.07 & 8.13 \\
\hline Standard deviation & 0.877 & 0.803 & 0.810 & 1.143 & 0.802 \\
\hline
\end{tabular}

TABLE 4: The optimized index system.

\begin{tabular}{|c|c|c|c|c|}
\hline Target & Criterion layer & Index layer & Indicator type & Data sources \\
\hline \multirow{14}{*}{ Supplier selection evaluation } & \multirow{3}{*}{ Technical skills } & Logistics facilities and equipment & Qualitative & Scoring by experts \\
\hline & & Proportion of supply chain management & Quantitative & Formula calculation \\
\hline & & Process integration capability & Qualitative & Scoring by experts \\
\hline & \multirow{3}{*}{ Teamwork ability } & Supply capacity & Qualitative & Scoring by experts \\
\hline & & Reliability & Qualitative & Scoring by experts \\
\hline & & Delivery accuracy & Quantitative & Formula calculation \\
\hline & \multirow{2}{*}{ Internal competitiveness } & Operating resources & Qualitative & Scoring by experts \\
\hline & & Production management ability & Qualitative & Scoring by experts \\
\hline & \multirow{3}{*}{ External competitiveness } & Organizational effectiveness analysis & Qualitative & Scoring by experts \\
\hline & & Customer needs and feedback & Qualitative & Scoring by experts \\
\hline & & Transportation cost & Quantitative & Formula calculation \\
\hline & \multirow{3}{*}{ Price factor } & Storage cost & Quantitative & Formula calculation \\
\hline & & Quality cost & Quantitative & Formula calculation \\
\hline & & Out-of-stock cost & Quantitative & Formula calculation \\
\hline
\end{tabular}


TABLE 5: Pairwise comparison matrix of expert group 1's evaluation of criterion-level indicators.

\begin{tabular}{ccccccc}
\hline$B_{i}$ & $B_{1}$ & $B_{2}$ & $B_{3}$ & $B_{4}$ & $B_{5}$ \\
\hline$B_{1}$ & 1 & 3 & 2 & 2 & $1 / 2$ & 0.252 \\
$B_{2}$ & $1 / 3$ & 1 & 1 & 3 & $1 / 2$ & 0.173 \\
$B_{3}$ & $1 / 2$ & 1 & 1 & 2 & $1 / 3$ & 0.143 \\
$B_{4}$ & $1 / 2$ & $1 / 3$ & $1 / 2$ & 4 & $1 / 4$ & 0.076 \\
$B_{5}$ & 2 & 2 & 3 & 4 & 1 & 0.356 \\
\hline
\end{tabular}

Note: the eigenvalue of the matrix is 5.200; the matrix consistency is 0.045 which is less than 0.1. Expert Group 1: $=(0.252,0.173,0.143,0.076,0.356)$. Expert Group 2: $=(0.220,0.228,0.099,0.065,0.388)$. Expert Group $3:=(0.187,0.348,0.063,0.107,0.295)$. Expert Group $4:=(0.241,0.199,0.118,0.072,0.370)$. Expert Group $5:=(0.241,0.115,0.076,0.199,0.369)$.

Expert Group 1: $w i=(0.252,0.173,0.143,0.076,0.356)$

Expert Group 2: $w i=(0.220,0.228,0.099,0.065,0.388)$

Expert Group 3: $w i=(0.187,0.348,0.063,0.107,0.295)$

Expert Group 4: $w i=(0.241,0.199,0.118,0.072,0.370)$

Expert Group 5: $w i=(0.241,0.115,0.076,0.199,0.369)$

Using the geometric mean, the final weight of the B-level indicators can be determined as

$$
\begin{aligned}
& u_{j}=\left[\prod_{i=1}^{m} w_{i}\right] \frac{1}{m}, \\
& u_{B}=(0.231,0.210,0.105,0.100,0.354) .
\end{aligned}
$$

The same method is used to calculate the weighted hypermatrix of all indicators. From the limit matrix, all indicator weights between indicators can be obtained as shown in Table 6 and Figure 1.

The top seven indicators are product cost, out-of-stock cost, transportation cost, quality cost, delivery accuracy, supply capacity, and reliability.

\section{MOP Model Construction}

We establish a specific model for chain convenience store purchasing supplier selection and purchasing volume allocation.

3.1. Meaning of Symbols. The mathematical symbols of the following model are defined as follows:

(1) Two types of decision variables:

One is the allocation ratio $x_{i j}\left(0<x_{i j}<1\right)$ of the purchased quantity when purchasing goods from each candidate supplier $g_{i}$; the other is the variable $y_{i j}=1$ that indicates whether the company purchases product $j$ from a supplier $g_{i}$, if the company purchases product $j$ from that supplier, then $y_{i j}=1$, otherwise $y_{i j}=0$, where $\mathrm{i}$ is the serial number of the supplier, $i=1,2, \ldots, \mathrm{m}, j$ is the serial number of the purchased product, $j=1,2, \ldots, n$.

(2) Parameter description:

$c_{j}$ : the total amount of the company's purchase of product $j$ during the planning period; $u_{i j}$ : the minimum purchase cost required for the product $j$ purchased by the supplier $g_{i} ; k_{i j}$ : the maximum supply of product $j$ provided by the supplier $g_{i}$;
TABLE 6: Index weights of the index layer.

\begin{tabular}{lcc}
\hline Name & $\begin{array}{c}\text { Weighted } \\
\text { value }\end{array}$ & $\begin{array}{c}\text { Limit } \\
\text { value }\end{array}$ \\
\hline $\begin{array}{l}\text { Logistics facilities and equipment } \\
\text { Proportion of supply chain }\end{array}$ & 0.30647 & 0.04045 \\
management & 0.28752 & 0.04076 \\
Process integration capability & 0.40601 & 0.04385 \\
Supply capacity & 0.35325 & 0.05102 \\
Reliability & 0.22543 & 0.05023 \\
Delivery accuracy & 0.42132 & 0.06102 \\
Operating resources & 0.54124 & 0.00731 \\
Production management ability & 0.45876 & 0.03621 \\
Organizational effectiveness analysis & 0.44676 & 0.00821 \\
Customer needs and feedback & 0.55324 & 0.03205 \\
Transportation cost & 0.22432 & 0.13385 \\
Storage cost & 0.33492 & 0.24137 \\
Quality cost & 0.21975 & 0.11265 \\
Out-of-stock cost & 0.22101 & 0.14102 \\
\hline
\end{tabular}

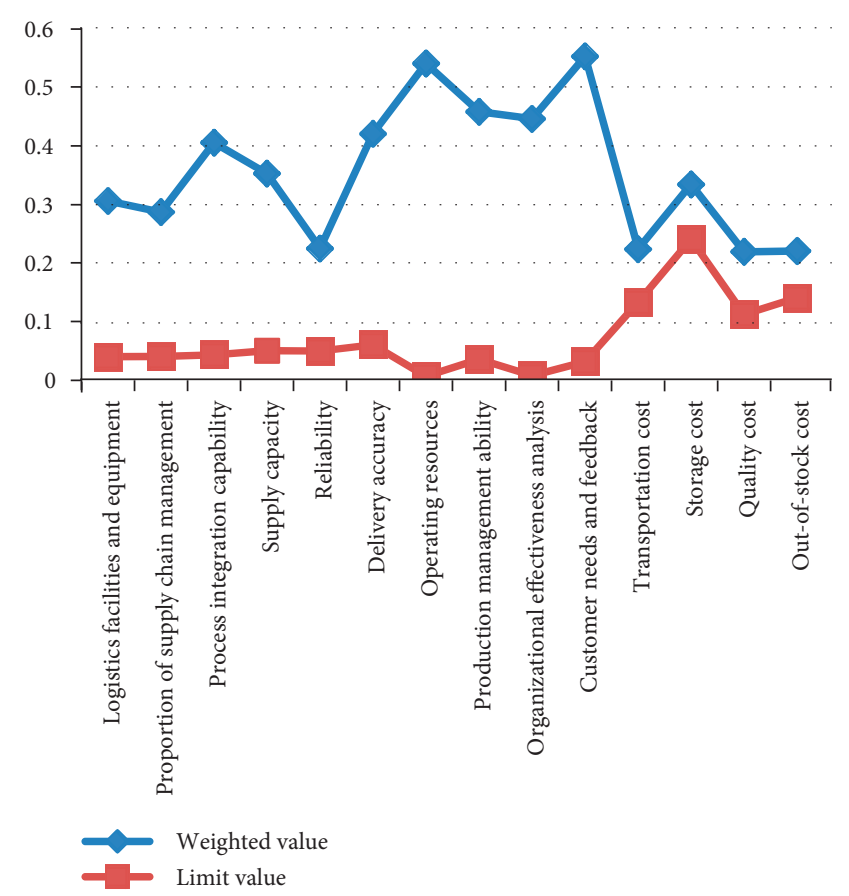

Figure 1: Index weight distribution chart of the index layer.

$n_{i}$ : the company can choose the number of suppliers; $n$ : the number of products that the company intends to purchase; $q_{i j}$ : the importance factor of the products provided by the supplier $g_{i} ; j_{i j}$ the product cost of buying $j$ products from the 
supplier $g_{i} ; j_{i}$ : the company expects to limit the maximum cost of the supplier's product $j . t_{i j}$ : the out-of-stock cost when the $g_{i}$ supplier provides the $j$ product; $t_{j}$ : the maximum outof-stock cost when the company limits the $g_{i}$ supplier to provide the $j$ product; $d_{i j}$ : the transportation of the $j$ product purchased from the $g_{i}$ supplier cost; $d_{j}$ : the highest transportation cost of the company's purchase of $j$ product limited by the $g_{i}$ supplier; $l_{i j}$ : the quality cost of the $j$ product purchased by the $g_{i}$ supplier; $l_{j}$ : the highest quality cost of the company's limited $g_{i}$ supplier $j$ product; $r_{i j}: g_{i}$ supplier $j$ product delivery accuracy rate; $r_{j}$ : represents the lowest delivery accuracy rate that the company expects supplier $j$ 's product; $e_{i j}: g_{i}$ supplier $j$ 's product supply capacity; $\mathrm{e}_{j}$ : the company expects the minimum supply capacity of $g_{i}$ supplier; $n_{i j}$ : the reliability of the product provided by the supplier $g_{i}$; $n_{j}$ : indicates the lowest limit of the reliability of the product expected by the supplier $g_{i}$ to provide $j ; p_{i j}$ : the proportion of the purchase cost of the $g_{i}$ supplier's purchase of $j$ products.

3.2. Model Establishment. According to the concept and symbolic assumptions of cooperation with essential suppliers, the following MOP models for supplier selection can be established:

(1) Objective function:

$$
\begin{aligned}
& \max Z_{1}=-\sum_{i=1}^{m} \sum_{j=1}^{n} p_{i j} x_{i j}, \\
& \max Z_{2}=\sum_{i=1}^{m} \sum_{j=1}^{n} q_{i j} x_{i j} .
\end{aligned}
$$

(2) Constraints:

St:

$$
\begin{aligned}
& u_{i j} \leq c_{j} x_{i j} \leq k_{i j}, \\
& \sum_{i=1}^{m} \sum_{j=1}^{n} f_{i j} x_{i j} \leq f_{j}, \\
& \sum_{i=1}^{m} \sum_{j=1}^{n} t_{i j} x_{i j} \leq t_{j}, \\
& \sum_{i=1}^{m} \sum_{j=1}^{n} d_{i j} x_{i j} \leq d_{j}, \\
& \sum_{i=1}^{m} \sum_{j=1}^{n} l_{i j} x_{i j} \leq l_{j}, \\
& \sum_{i=1}^{m} \sum_{j=1}^{n} r_{i j} x_{i j} \leq r_{j}, \\
& \sum_{i=1}^{m} \sum_{j=1}^{n} e_{i j} x_{i j} \leq e_{j},
\end{aligned}
$$

$$
\begin{aligned}
\sum_{i=1}^{m} \sum_{j=1}^{n} r_{i j} x_{i j} & \leq r_{j}, \\
\sum_{i=1}^{m} x_{i j} & =1, \\
x_{i j}\left(y_{i j}-1\right) & =0, \\
x_{i j} & \in(0,1), \\
y_{i j} & \in(0,1) .
\end{aligned}
$$

\section{(3) Formula meaning:}

Formula (4): represents the lowest purchasing cost.

Formula (5): represents the amount of priority to purchase from $g_{i}$ suppliers when purchasing product $j$.

Formula (6): the upper and lower limits of the ability of supplier $g_{i}$ to provide products.

Formula (7): the product cost constraint when supplier $g_{i}$ purchases product $j$.

Formula (8): the constraint of the out-of-stock cost when supplier $g_{i}$ purchases product $j$.

Formula (9): the transportation cost constraint when supplier $g_{i}$ purchases product $j$.

Equation (10): constraint of quality cost when $g_{i}$ supplier purchases product $j$.

Equation (11): constraint on the delivery accuracy of product $j$ of $g_{i}$ supplier.

Formula (12): requirements for the supply capacity of $g_{i}$ supplier $j$ 's products.

Formula (13): $g_{i}$ supplier provides product $j$ reliability requirements.

Equation (14): when purchasing product $j$ from the $g_{i}$ supplier, $y_{i j}$ must be 1 .

\section{Lawson Convenience Store Supplier Evaluation Selection}

4.1. The Weight of Index System Determined Based on ANP Model. According to the indicator system constructed in the previous paper and the determination of related weights, the relevant data are substituted for the evaluation and selection of Lawson convenience store suppliers [22-26], and now 5 suppliers $=\left(g_{1}, g_{2}, g_{3}, g_{4}, g_{5}\right)$ are screened and one is selected as a partner of the company; a tripartite group $\left(p_{1}, p_{2}, p_{3}, p_{4}, p_{5}\right)$ is formed by a team of senior purchasers, a team of logistics managers, and a team of experts in related industries. The expert group decided to select the top seven indicators to evaluate the five suppliers. The weights of the tripartite experts in the decision-making are: senior purchaser team $\Phi=0.5$, logistics manager team $\Phi=0.3$, and related industry expert team $\emptyset=0.2$. In the evaluation index, the evaluation data of five quantitative indicators come from 5 procurement suppliers, where product cost, out-of-stock cost, quality cost, and transportation cost are the ratios of the 
average cost of the four products to the related expenses in the same industry, which are shown in Table 7 and Figure 2.

The tripartite experts score the supplier's performance under the qualitative indicators and the data of all qualitative indicators. The scoring adopts a nine-point system. The supplier's performance is represented by 9-1 from high to bottom. 9 points means very good, and 1 point represents extremely poor performance. The larger the score, the better the performance.

The three-party experts' specific scores on the 5 candidates for selection and the final scores after calculation are shown in Table 8 and Figure 3.

The first step is to determine the weights. In the previous paper, the results of ANP have been obtained and the weights of the seven evaluation indicators are

$W=(0.24137,0.14102,0.13385,0.11265,0.06102,0.05102,0.05023)$

The second step is to construct an evaluation matrix of five procurement suppliers under seven evaluation indicators in the software.

The third step is to define the attributes of the index evaluation. For each evaluation index, define its evaluation attribute and construct the evaluation attribute matrix for pairwise comparison.

The fourth step is to sort the suppliers, input the final score value of each supplier, and further comprehensively calculate the corresponding ranking result: $g_{1}>g_{2}>g_{5}>g_{3}>g_{4}$, and you can get 5 purchases. The supplier's importance coefficient is $q=(0.23310,0.23193$, $0.18241,0.17214,0.21423)$.

\subsection{Purchase Volume Allocated Based on MOP}

4.2.1. Data Collection. There are too many types of chain convenience stores. Here, 4 of them are selected as an example [27]. Substitute the 5 buyers qualified in the preliminary selection and sorted into the model and calculate and evaluate further. The parameter values and evaluation information of each supplier's supply capacity and level and the parameter values required by retail enterprises for the supplier's supply capacity and level are shown in Tables 9 and 10 .

4.2.2. Data Processing. According to the symbols established in formulas (4) to (17) and the supplier's importance coefficient established in the previous article, the MOP model that can be established is as follows:

$$
\begin{aligned}
\max z_{1} & =\left(0.12 x_{11}+0.11 x_{21}+0.15 x_{32}+0.14 x_{52}+0.13 x_{23}+0.12 x_{33}+0.11 x_{14}+0.12 x_{44}\right) \\
\max z_{2} & =0.233 x_{11}+0.232 x_{21}+0.18 x_{32}+0.214 x_{52}+0.232 x_{23}+0.182 x_{33}+0.233 x_{14}+0.138 x_{44} \\
& 9 \leq 20 x_{11} \leq 15,7 \leq 20 x_{21} \leq 13, x_{32} \leq 10,8 \leq x_{52} \leq 11 \\
& 5 \leq 15 x_{23} \leq 12,5 \leq 20 x_{21} \leq 13,6 \leq 10 x_{14} \leq 8,4 \leq 10 x_{44} \leq 5 \\
& 6 x_{11}+4 x_{21} \leq 7,5 x_{32}+4 x_{52} \leq 5,3 x_{23}+3 x_{33} \leq 6,3 x_{14}+2 x_{44} \leq 5 \\
& x_{11}+0.5 x_{21} \leq 1.2, x_{32}+0.5 x_{52} \leq 0.8,0.5 x_{32}+0.5 x_{33} \leq 1,0.5 x_{14}+0.5 x_{44} \leq 0.7 \\
& 0.2 x_{11}+0.1 x_{21} \leq 0.5,0.2 x_{32}+0.1 x_{52} \leq 0.4,0.1 x_{32}+0.1 x_{33} \leq 0.4,0.1 x_{14}+0.1 x_{44} \leq 0.3 \\
& 0.9 x_{11}+0.95 x_{21} \geq 0.95,7 x_{32}+7 x_{52} \geq 9,8 x_{32}+6 x_{33} \geq 9.7 x_{14}+6 x_{44} \geq 8 \\
\text { s.t. } \quad & 7 x_{11}+8 x_{21} \geq 8,7 x_{32}+6 x_{52} \geq 9,7 x_{32}+6 x_{33} \geq 9.6 x_{14}+7 x_{44} \geq 8 \\
& x_{11}+x_{21}=1, x_{32}+x_{52}=1, x_{23}+x_{33}=1, x_{14}+x_{44}=1 \\
& x_{11} \times\left(y_{11}-1\right)=0, x_{21} \times\left(y_{21}-1\right)=0, x_{32} \times\left(y_{32}-1\right)=0, x_{52} \times\left(y_{52}-1\right)=0 \\
& x_{23} \times\left(y_{23}-1\right)=0, x_{33} \times\left(y_{33}-1\right)=0, x_{14} \times\left(y_{14}-1\right)=0, x_{44} \times\left(y_{4}-1\right)=0 \\
& 0 \leq x_{i j} \leq 1,0 \leq y_{i j} \leq 1 \\
& i=1.2, \ldots, 5, j=1.2, \ldots, 4 .
\end{aligned}
$$


TABLE 7: Five quantitative indicators of five suppliers.

\begin{tabular}{lccccc}
\hline & $g_{1}$ & $g_{2}$ & $g_{3}$ & $g_{4}$ & \\
\hline Storage cost & $65 \%$ & $60 \%$ & $70 \%$ & $58 \%$ & $76 \%$ \\
Out-of-stock cost & $60 \%$ & $64 \%$ & $65 \%$ & $60 \%$ & $68 \%$ \\
Transportation cost & $60 \%$ & $58 \%$ & $72 \%$ & $55 \%$ & $59 \%$ \\
Quality cost & $59 \%$ & $67 \%$ & $92 \%$ & $75 \%$ \\
Delivery accuracy & $97 \%$ & $96 \%$ & $91 \%$ \\
\hline
\end{tabular}

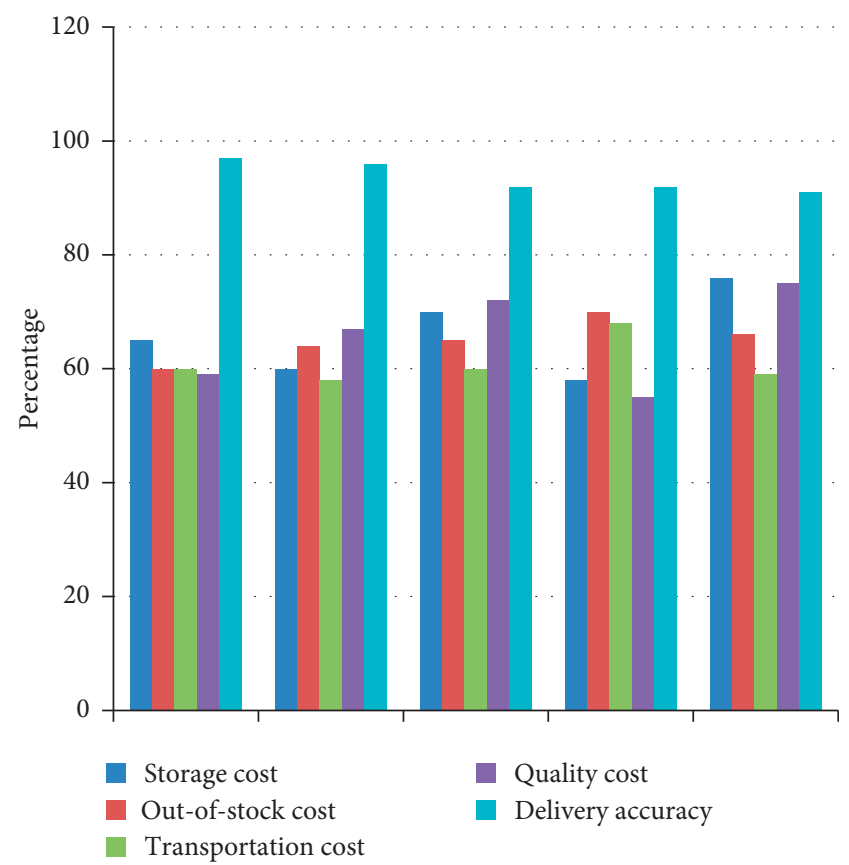

FIgURe 2: Distribution map of five quantitative indicators of five suppliers.

TABLE 8: Specific scoring results of 5 candidate suppliers.

\begin{tabular}{lccccc}
\hline & $g_{1}$ & $g_{2}$ & $g_{3}$ & $g_{4}$ & $g_{5}$ \\
\hline Storage cost & 8 & 7.7 & 6.3 & 3.8 & 6.5 \\
Out-of-stock cost & 7.7 & 6.8 & 5 & 4.5 & 7.1 \\
Transportation cost & 7.3 & 8 & 6.4 & 6.5 & 7 \\
Quality cost & 6.7 & 5.9 & 6 & 6.7 & 6.7 \\
Delivery accuracy & 6.6 & 7.3 & 5.7 & 6.2 & 6.5 \\
Supply capacity & 8.5 & 7.2 & 5.5 & 6.4 & 6.5 \\
Reliability & 7.1 & 6.8 & 6.4 & 5.7 & 7.1 \\
\hline
\end{tabular}

4.2.3. Solution. According to the algorithm introduced in the previous paper, we can solve

$$
\begin{aligned}
& z_{1}{ }^{*}=49.1 \%, \\
& x_{11}=0.427, \\
& x_{21}=0.573, \\
& x_{32}=0.516, \\
& x_{52}=0.484 \\
& x_{23}=0.785, \\
& x_{33}=0.215, \\
& x_{14}=0.548, \\
& x_{44}=0.452 \\
& y_{11}=1, \\
& y_{21}=1, \\
& y_{32}=1, \\
& y_{52}=1, \\
& y_{23}=1, \\
& y_{33}=1, \\
& y_{14}=1, \\
& y_{44}=1,
\end{aligned}
$$

and adopt $\lambda=0.05$. Then, the above model can be further transformed into the following form:

$$
\begin{aligned}
\max z_{2}= & 0.233 x_{11}+0.232 x_{21}+0.182 x_{32}+0.214 x_{52} \\
& +0.232 x_{23}+0.182 x_{33}+0.233 x_{14}+0.138 x_{44}
\end{aligned}
$$

The constraint condition is added on the original basis, namely: 


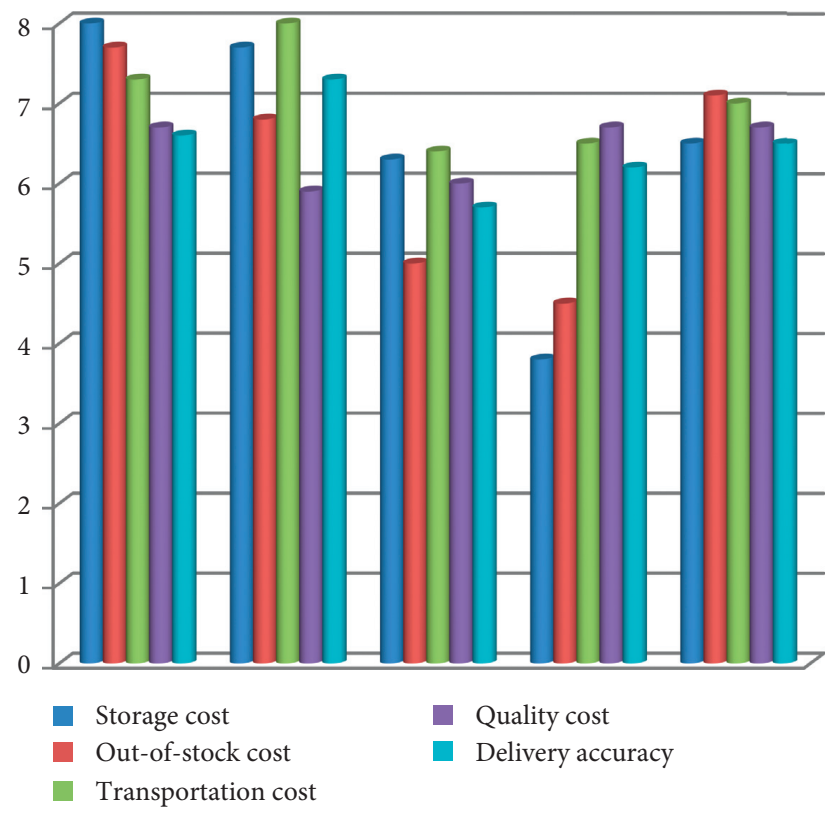

Figure 3: Distribution of specific scoring results of 5 candidate suppliers.

TABle 9: Parameter values and evaluation information for marking the supply capacity and level of each supplier.

\begin{tabular}{|c|c|c|c|c|c|c|c|c|c|c|c|c|}
\hline $\begin{array}{l}\text { Product } \\
\text { serial } \\
\text { number }\end{array}$ & Supplier & $\begin{array}{c}p_{i j} \\
(\%)\end{array}$ & $\begin{array}{c}q_{i j} \\
(\%)\end{array}$ & $\begin{array}{c}k_{i j} \text { (ten } \\
\text { thousand } \\
\text { yuan) }\end{array}$ & $\begin{array}{c}u_{i j}(\text { ten } \\
\text { thousand } \\
\text { yuan) }\end{array}$ & $\begin{array}{c}f_{i j}(\text { ten } \\
\text { thousand } \\
\text { yuan })\end{array}$ & $\begin{array}{c}t_{i j} \text { (ten } \\
\text { thousand } \\
\text { yuan) }\end{array}$ & $\begin{array}{c}d_{i j} \text { (ten } \\
\text { thousand } \\
\text { yuan) }\end{array}$ & $\begin{array}{c}l_{i j} \text { (ten } \\
\text { thousand } \\
\text { yuan) }\end{array}$ & $\begin{array}{l}r_{i j} \\
(\%)\end{array}$ & $e_{i j}$ & $n_{i j}$ \\
\hline \multirow{2}{*}{1} & 1 & 12 & 23.3 & 15 & 9 & 6 & 1 & 0.2 & 0.1 & 90 & 6 & 7 \\
\hline & 2 & 11 & 23.2 & 13 & 7 & 4 & 0.5 & 0.1 & 0.1 & 95 & 8 & 8 \\
\hline \multirow{2}{*}{2} & 3 & 15 & 22.3 & 10 & 8 & 5 & 1 & 0.2 & 0.12 & 90 & 7 & 7 \\
\hline & 5 & 14 & 22.5 & 11 & 8 & 4 & 0.5 & 0.1 & 0.15 & 90 & 7 & 6 \\
\hline \multirow{2}{*}{3} & 2 & 13 & 18.9 & 12 & 5 & 3 & 0.5 & 0.1 & 0.1 & 95 & 8 & 7 \\
\hline & 3 & 12 & 19.2 & 8 & 5 & 3 & 0.5 & 0.1 & 0.12 & 90 & 6 & 6 \\
\hline \multirow{2}{*}{4} & 1 & 11 & 21.5 & 8 & 6 & 3 & 0.5 & 0.1 & 0.05 & 90 & 7 & 6 \\
\hline & 4 & 12 & 20.2 & 5 & 4 & 2 & 0.5 & 0.1 & 0.05 & 95 & 6 & 5 \\
\hline
\end{tabular}

TABLE 10: The requirements of a retail company on the supply capacity of its suppliers.

\begin{tabular}{lcccccccc}
\hline Purchase products (ten thousand yuan) & $c_{j}$ & $f_{j}$ & $t_{j}$ & $d_{j}$ & $r_{j}$ & $e_{j}$ & $l_{j}$ & $n_{j}$ \\
\hline 1 & 20 & 7 & 1.2 & 0.5 & 95 & 8 & 0.5 \\
2 & 12 & 5 & 0.8 & 0.4 & 92 & 9 & 0.3 & 9 \\
3 & 15 & 6 & 1 & 0.4 & 95 & 9 & 0.2 & 9 \\
4 & 10 & 5 & 0.7 & 0.3 & 95 & 8 & 0.3 & 8 \\
\hline
\end{tabular}




$$
\begin{gathered}
0.12 x_{11}+0.11 x_{21}+0.15 x_{32}+0.14 x_{52}+0.13 x_{23}+0.12 x_{33} \\
+0.11 x_{14}+0.12 x_{44} \leq(1-\lambda) \times 49.1 \% .
\end{gathered}
$$

The solution of the single objective mathematical programming model is

$$
\begin{aligned}
& x_{11}=0.712, \\
& x_{21}=0.288, \\
& x_{32}=0.195, \\
& x_{52}=0.805, \\
& x_{23}=0.751, \\
& x_{33}=0.249, \\
& x_{14}=0.378, \\
& x_{44}=0.622, \\
& y_{11}=1, \\
& y_{21}=1, \\
& y_{32}=1, \\
& y_{52}=1, \\
& y_{23}=1, \\
& y_{33}=1, \\
& y_{14}=1, \\
& y_{44}=1 .
\end{aligned}
$$

\section{The Data Analysis}

From the above calculation results, it can be seen that the best procurement plan for the company when purchasing product 1 is to choose $g_{1}$ and $g_{2}$ suppliers, and the optimal procurement volume is $71.2 \%$ for $g_{1}$ and $28.8 \%$ for $g_{2}$; when the company purchases product 2 , the best procurement plan is to choose $g_{3}$ and $g_{5}$ suppliers. The best procurement volume is $19.5 \%$ for $g_{3}$ and $80.5 \%$ for $g_{5}$. The best solution for the company to purchase product 3 is to choose $g_{2}$ and $g_{3}$ as suppliers, and the optimal purchase quantity is $75.1 \%$ for $g_{2}$ and $24.9 \%$ for $g_{3}$. The best solution for the company to purchase product 4 is to choose $g_{1}$ and $g_{4}$ as suppliers, and the optimal purchase quantity is $37.8 \%$ for $g_{1}$ and $62.2 \%$ for $g_{4}$.

Based on the above analysis, the total procurement costs of these five suppliers are calculated as follows:

$$
\begin{aligned}
& \mathrm{M}\left(g_{1}\right)=0.712 * 20+0.378 * 10=19.02, \\
& \mathrm{M}\left(g_{2}\right)=0.288 * 20+0.751 * 15=17.025, \\
& \mathrm{M}\left(g_{3}\right)=0.195 * 12+0.249 * 15=6.075, \\
& \mathrm{M}\left(g_{4}\right)=0.622 * 10=6.22, \\
& \mathrm{M}\left(g_{5}\right)=0.805 * 12=9.66
\end{aligned}
$$

Through the calculation of the procurement costs of the above suppliers, when the purchase cost is constant, the higher the company's purchase cost for a certain supplier, the more transactions the supplier has with the company, and the more important it is to the company. [28-31], so it can be concluded that the order of the 5 suppliers to be selected is $g_{1}>g_{2}>g_{5}>g_{3}>g_{4}$. According to the situation of these 5 suppliers, a multiobjective mathematical programming model is established to calculate the distribution of the calculated purchase amount. From the above calculation results, it can be seen that the procurement expenditures of the 5 suppliers are basically in line with the importance of the suppliers in the previous section, and the amount is $g$, which accounts for 190,200 RMB, 170,250RMB, 60,750 RMB, 62,200RMB, and 96,600 RMB.

\section{Conclusion}

Reasonably reducing the purchase cost while ensuring the level of service quality is always a problem to be solved by chain convenience stores. This paper constructs ANP to select the chain convenience store supplier indicators, takes the Lawson convenience store as an example to collect relevant data, and combines the MOP to choose and rank Lawson chain convenience store suppliers. Then, the reasonable selection of Rosen's suppliers is carried out to determine the procurement allocation of each supplier, to provide a theoretical basis for the later maintenance of suppliers, which is helpful for the supervision and classification management of suppliers, ensuring the supply quality of suppliers, deepening the cooperation with suppliers, controlling the procurement cost, and effectively improving the service level and competitiveness of enterprises. Existing research has neglected the importance of suppliers and later management. This article considers the service level quality while considering the purchase cost, which has certain guiding significance for the development of modern enterprises. At the same time, it also verified that the established model is scientific and practical. With the continuous changes in consumer demand, multiple goals can be incorporated in the future to select and manage the suppliers of chain retail stores.

\section{Data Availability}

All of the underlying data supporting the results of this study are publicly available online and can be easily accessed.

\section{Conflicts of Interest}

The authors declare that they have no conflicts of interest.

\section{Acknowledgments}

This study was supported by Anhui Province Key Research and Development Program Project (grant no. 201904a05020091) and its supporting projects (grant no. PT04a05020094), Natural Science Research Project of Anhui Universities in 2020 (grant no. KJ2020A0680), Chaohu University Discipline Construction Quality Improvement Project in 2020 (grant no. kj20xqyx03), Chaohu University Natural Science Research (grant no. XWY-201801), a key project of Chaohu University Natural Science Research 
(grant no. XLZ-201905), and a scientific research project commissioned by Hefei Hongzu Education Technology Co., Ltd (grant no. hxkt20210001).

\section{References}

[1] N. Merino, M. Marín, M. Fuentes et al., "Information and digital technologies of Industry 4.0 and Lean supply chain management: a systematic literature review," International Journal of Production Research, vol. 58, no. 16, 2020.

[2] Y. Li, "Research on supply chain CSR management based on differential game," Journal of Cleaner Production, vol. 268, 2020.

[3] B. Sarkar, M. Sarkar, B. Ganguly et al., "Combined effects of carbon emission and production quality improvement for fixed lifetime products in a sustainable supply chain management," International Journal of Production Economics, vol. 231, 2021.

[4] N. Guo, "research on optimization of supplier selection for A retail enterprise based on analytic hierarchy process," China Logistics and Procurement, vol. 7, pp. 71-73, 2020.

[5] J. Liao and R. Zhang, "Research on evaluation and selection of green suppliers of papermaking enterprises based on AHPTOPSIS method," Logistics Engineering and Management, vol. 42, no. 02, pp. 91-93, 2020.

[6] S. Zhou and J. Liao, "Research on evaluation and selection of green suppliers of pharmaceutical enterprises based on AHP method," Logistics Technology, vol. 42, no. 10, pp. 28-31, 2020.

[7] B. Song, "Research on evaluation and selection of suppliers in L supermarket," Henan University of Technology, vol. 7, 2019.

[8] M. Modak, S. Sinha, A. Raj et al., "Corporate social responsibility and supply chain management: framing and pushing forward the debate," Journal of Cleaner Production, vol. 141, p. 273, 2020.

[9] C. Machado, M. Vivaldini, and O. Oliveira, "Production and supply-chain as the basis for SMEs' environmental management development: a systematic literature review," Journal of Cleaner Production, vol. 1, p. 273, 2020.

[10] M. Beheshti, J. Clelland, and K. Harrington, "Competitive advantage with vendor managed inventory," Journal of Promotion Management, vol. 26, no. 6, 2020.

[11] J. Lee and G. Johnson, "Contracting for vendor-managed inventory with a time-dependent stockout penalty," International Transactions in Operational Research, vol. 27, no. 3, 2020.

[12] D. Maio and D. Laganà, "The effectiveness of vendor managed inventory in the last-mile delivery: an industrial application," Procedia Manufacturing, vol. 42, 2020.

[13] L. Lin, "Application of analytic hierarchy process in supplier selection-taking $\mathrm{M}$ food manufacturing enterprise as an example," Modern Commerce, vol. 7, pp. 32-33, 2020.

[14] P. Liu, C. Wei, J. Liu et al., "Using Analytic Hierarchy Process to select suppliers for project procurement," China Management Information, vol. 23, no. 9, pp. 111-113, 2020.

[15] D. Li and G. Chen, "Construction of evaluation index system for selection of agricultural products cold chain logistics suppliers," Market Research, vol. 6, pp. 64-65, 2019.

[16] Y. Zhang, K. Wang, Q. He et al., "Covering-based web service quality prediction via neighborhood-aware matrix factorization," IEEE Transactions on Services Computing, vol. 1, 2019.

[17] L. Pan, "Analysis on the selection and evaluation of suppliers by using activity-based costing," Accounting Learning, vol. 17, pp. 167-169, 2020.
[18] W. Tong, "Research on supplier evaluation and selection of MC enterprises in the environment of internet of things," Donghua University, vol. 8, 2019.

[19] X. Han, "Research on supplier selection under multiple constraints based on genetic algorithm," Value Engineering, vol. 39, no. 14, pp. 123-124, 2020.

[20] Y. Xu, "Research on E-commerce supplier selection based on big data analysis Technology," Modern Electronic Technology, vol. 43, no. 15, pp. 152-158, 2020.

[21] G. Xiao and G. Zhang, "Supplier selection and coordination of B2C enterprises based on green supply chain theory," Business Economic Research, vol. 3, pp. 127-129, 2020.

[22] W. Luong, "A vendor managed inventory policy with emergency orders," Journal of Industrial and Production Engineering, vol. 37, pp. 2-3, 2020.

[23] Q. Wei, J. Zhang, G. Zhu et al., "Vendor managed inventory with considering stochastic learning effect," Journal of the Operational Research Society, vol. 71, no. 4, 2020.

[24] S. Amiri, A. Zahedi, M. Kazemi et al., "Determination of the optimal sales level of perishable goods in a two-echelon supply chain network," Computers \& Industrial Engineering, vol. 139, 2020.

[25] H. Golpîra, "Optimal integration of the facility location problem into the multi-project multi-supplier multi-resource Construction Supply Chain network design under the vendor managed inventory strategy," Expert Systems With Applications, vol. 139, 2020.

[26] Q. Chen and Z. Zeng, "Supplier selection and evaluation based on partnership," Car Practical Technology, vol. 14, pp. 219221, 2020.

[27] Y. Zhang, J. Pan, L. Qi, and Q. He, "Privacy-preserving quality prediction for edge-based IoT services," Future Generation Computer Systems, vol. 114, pp. 336-348, 2021.

[28] S. Khoshfetrat, M. Rahiminezhad Galankashi, and M. Almasi, "Sustainable supplier selection and order allocation: a fuzzy approach," Engineering Optimization, vol. 52, no. 9, pp. 1494-1507, 2020.

[29] D. He, Research on Improvement of Supplier Evaluation of A Company, Jilin University, Changchun, China, 2020.

[30] M. Zhao, "Application of triangular intuitionistic fuzzy number theory in supplier selection," Wireless Internet Technology, vol. 17, no. 05, pp. 166-168, 2020.

[31] O. Olanrewaju, Z. Dong, and S. Hu, "Supplier selection decision making in disaster response," Computers \& Industrial Engineering, vol. 143, 2020. 